\title{
Factors influencing male affiliation and coalitions in a species with male dispersal and intense male-male competition, Colobus vellerosus
}

\author{
Julie A. Teichroeb ${ }^{\mathrm{a}, \mathrm{b}, *}$, Eva C. Wikberg ${ }^{\mathrm{c}, \mathrm{d}}$, Nelson Ting ${ }^{\mathrm{e}}$ and Pascale Sicotte $^{\mathrm{c}}$ \\ ${ }^{a}$ Department of Anthropology, University of California, Santa Cruz, \\ 1156 High Street, Santa Cruz, CA 95064, USA \\ b Department of Anthropology, McGill University, 855 Sherbrooke Street W., \\ Montreal, QC, Canada H3A 2T7 \\ ${ }^{c}$ Department of Anthropology, University of Calgary, 2500 University Dr. N.W., \\ Calgary, AB, Canada T2N 1N4 \\ ${ }^{\mathrm{d}}$ Department of Integrated Biosciences, University of Tokyo, Seimeitou 502, \\ 5-5-5 Kashiwanoha, Kashiwa, Chiba 277-8562, Japan \\ ${ }^{\mathrm{e}}$ Department of Anthropology, Institute of Ecology and Evolution, University of Oregon, \\ 308 Condon Hall, 1218 University of Oregon, Eugene, OR 97403, USA \\ *Corresponding author's e-mail address: jteichro@ucsc.edu
}

Accepted 11 April 2013

\begin{abstract}
Male Colobus vellerosus compete intensely for access to females, which sometimes leads to mortal wounding. Yet, males often form cooperative relationships to overtake prime-aged males and immigrate into bisexual groups. We investigated the factors that predicted the presence of coalitions and affiliative relationships among males in this species. Interactions among males in 292 dyads from six groups were examined from 2004 to 2010 at Boabeng-Fiema, Ghana. Affiliation rates among males were higher and aggression rates lower when one or both males in the dyad were subadult, compared to adult male dyads. Affiliation rates tended to be higher among males that were kin but no other aspect of male relationships predicted affiliation. Coalitions among males were rarely observed and primarily occurred in the context of joint defense against extra-group males $(93.5 \%$ of events). Adult males were more likely to provide coalitionary support than subadults and coalitions occurred significantly more often when both males were high ranking, since these males probably benefited most in terms of reproductive success from excluding extra-group males. Rank-changing and leveling coalitions among low-ranking males appear to be quite rare or absent in C. vellerosus. The costs of these types of coalitions may be too high or male group size too small on average for these types of coalitions to have been selected for. The overall low rates of affiliation and coalitions among male $C$. vellerosus are likely influenced by male-biased dispersal and the high level of male-male competition.
\end{abstract}




\section{Keywords}

colobines, male affiliation, coalition formation, male-male competition, male dispersal.

\section{Introduction}

Affiliative relationships among male mammals are not typical compared to those among females owing to the higher frequency of male dispersal and the greater intensity of intra-sexual competition for mates (Greenwood, 1980; van Hooff \& van Schaik, 1992; Silk, 1994; Isbell \& Van Vuren, 1996). Strong male relationships are typically only expected to occur in male philopatric species (e.g., Brachyteles arachnoides, Strier, 1990; Ateles geoffroyi, Symington, 1990; Saimiri oerstedi, Boinski, 1994; Pan paniscus, Furuichi \& Ihobe, 1994; P. troglodytes, Goodall, 1986; Watts, 2000a). Nevertheless, for some species where males disperse from the natal group, affiliative relationships may exist among males that are often unrelated (e.g., Panthera leo, Schaller, 1972; Acinonyx jubatus, Caro \& Collins, 1987; Herpestes sanquineus, Rood, 1989; Helogale parvula, Rood, 1990; Tursiops aduncus, Connor et al., 1992; Möller \& Beheregaray, 2004; Macaca radiata, Silk, 1994; Adiseshan et al., 2011; M. assamensis, Schülke et al., 2010) or males that manage to maintain a long-term association by parallel transfer (e.g., Panthera leo, Packer \& Pusey, 1982; S. sciureus, Mitchell, 1994; Cebus capucinus, Jack \& Fedigan, 2004).

Social tolerance between males may lead to the formation of affiliative male-male relationships and potentially male coalitions. However, social tolerance is reliant on the presence of multi-male groups, which may form in several different ways in male dispersed species. A male's ability to monopolize a group of females depends largely on the spatial and temporal distribution of receptive females (Emlen \& Oring, 1977; Bissonnette et al., 2011) and his competitive potential (van Hooff \& van Schaik, 1994; Teichroeb et al., 2012). Groups with more females and species where female receptivity is temporally concentrated are more likely to show multi-male groupings because a single male cannot monopolize many females (Nunn, 1999; Cords, 2000). In a typical uni-male, multi-female system, multi-male groups may form due to male influxes, attempted takeovers by single males where the resident male remains in the group, takeovers by coalitions of extra-group males, or when males remain in their natal group past maturity creating age-graded groups (Dunbar, 1984; Pope, 1990; Sicotte, 1993; 
Cords, 2000; Sterck \& van Hooff, 2000; Watts, 2000b; Saj \& Sicotte, 2005; Dias et al., 2010). When males are able to co-reside in these types of multimale groups, male relationships may vary from simple mutual tolerance to the formation of strong affiliative bonds, which may include within-group coalitions against conspecifics, potentially with a preference for certain partners over others (Mitchell, 1994; van Hooff \& van Schaik, 1994; Olson \& Blumstein, 2009).

The types of male coalitions that are seen in multi-male groups depend upon the type and intensity of competition that is present and on female reproductive strategies (van Schaik et al., 2006). Strong within-group contest competition can lead to rank-changing male coalitions, while moderate within-group contest may lead to leveling male coalitions (Pandit \& van Schaik, 2003; van Schaik et al., 2006). For both rank-changing and leveling coalitions, the members of the coalition rank below the target. They differ in that rank-changing coalitions lead to a change in the dominance rank of at least one member of the coalition, while leveling coalitions do not lead to rank change but allow at least one member of the coalition to access limiting resources (Pandit \& van Schaik, 2003; van Schaik et al., 2006). When male reproductive competition within-group is mainly scramble (when females show synchronous estrus, engage in polyandrous mating, or show a long period of receptivity around ovulation), one expects within-group male coalitions to be directed towards reducing male group size, as male reproductive success will be influenced primarily by the number of male co-residents (Berghänel et al., 2010). In this competitive situation, most male coalitions are directed towards extra-group males to prevent male immigration (Pope, 1990; Dias et al., 2010).

The types of within-group coalitions and the conditions leading to their development are relatively well investigated in primates, though less so for other animals (reviewed in Smith et al., 2010). Population density and local demography are certainly factors influencing the frequency and duration of multi-male groups and hence the possibility of male-male affiliation and male coalitions (Pope, 1990; Hill, 1994; van Schaik et al., 2006; Higham $\&$ Maestripieri, 2010). There are also costs that may prevent the expression of male coalitions, such as the risk of injury if a coalition partner withdraws prior to the resolution of the conflict. This reinforces the notion that males need to have reliable partners for coalitions to occur (van Schaik et al., 2006). Finally, the frequency of male affiliation, as well as the type and 
the occurrence of male coalitions are affected by the degree of reproductive skew between males and the process by which it is attained (i.e., whether the alpha male benefits from the presence of subordinates or is unable to expel them; e.g., van Schaik et al., 2006; Bissonnette et al., 2009; Henzi et al., 2010). Less attention has been devoted to the conditions under which between-group male coalitions (where targets are individuals outside of the social group) develop in male dispersed species (cf., Sterck \& van Hooff, 2000, p. 129).

In this paper, we investigated the factors (i.e., age, rank, kinship, aggression rate, length of co-residency in a group, participation in parallel transfer) influencing affiliation and coalitions among males in multi-male groups of Colobus vellerosus (ursine colobus or white-thighed colobus) at the Boabeng-Fiema Monkey Sanctuary (BFMS) in Ghana. C. vellerosus is a species with male-biased and facultative female dispersal (Teichroeb et al., 2009, 2011; Wikberg et al., 2012) where females experience a high infanticide threat (Teichroeb \& Sicotte, 2008; Teichroeb et al., 2012) and mate polyandrously (Teichroeb \& Sicotte, 2010). There is strong, direct malemale competition (which sometimes leads to mortal wounding) for gaining residency in bi-sexual units (Sicotte et al., 2007; Teichroeb et al., 2011). A high-quality male may monopolize a group of females but few males have ever achieved this feat in the period between 2000 and 2012 (only 8.5\% of adult males in our research groups maintained residence as the single male of a uni-male group for more than 3 months, J.A.T. and E.C.W., unpubl. data; Teichroeb et al., 2012) and male tenure was short (24 months, $N=33$, Wikberg et al., 2012). The proportion of uni-male groups in the population at BFMS has ranged between 26 and 48\% since 2000 (Saj et al., 2005; Holmes, 2011) and multi-male groups contain an average of 3.5 adult males (9 groups over 237 months of observation; J.A.T. and E.C.W., unpubl. data). Multi-male groups seem to occur either as a result of large female group size, and/or of the inability of resident males to repel extra-group males (Teichroeb et al., 2011, 2012). Though multi-male groups have more females on average than uni-male groups ( 2.8 vs. 2.2 , respectively), the ratio of males to females is higher for uni-male than for multi-male groups $(0.4$ vs. 0.7, respectively; Holmes, 2011). This demonstrates either the monopolization abilities of high-quality males or alternatively, the fact that males in multi-male groups cannot evict one another and are not 'chosen' preferentially as a group by females. 
Groups of $C$. vellerosus at BFMS contain a mean of 1.9 subadult males (Range $0-9, N=237$ months, 9 groups; J.A.T. and E.C.W., unpubl. data). Subadult males disperse from their natal group at a mean age of five years but are not physically mature until around the age of seven (Teichroeb et al., 2011) and multi-male groups do not usually form due to male maturation in their natal group. Subadult males are always subordinate to adult males but may achieve some mating success in their natal and subsequent groups. While subadult males receive little aggression when they enter a new group and tend to stay low-ranking, adult males often immigrate and achieve high rank within a few months (Teichroeb et al., 2011), unlike the process documented in other species where males slowly rise in the ranks for years, during which females can mate with them (Clarke et al., 2009).

In multi-male groups of $C$. vellerosus, male rank does not influence mating frequency (Figure 1; Teichroeb \& Sicotte, 2010). This lack of association is surprising in light of the intense male-male competition for group membership that we have observed. Genetic data to determine reproductive skew is available for only one multi-male, multi-female group thus far. The alpha male was found to have sired $87.5 \%$ of the infants in this group (6 out of 7 infants; E.C.W., unpubl. data). Taken together, these results show that despite the lack of mating skew, there is nevertheless a reproductive skew in favor of alpha males. This suggests an effect of female strategies to distribute mating across males when possible, while concentrating their matings in the fertile period with alpha males. Alternatively, alpha males may be more successful in mate-guarding females during ovulation. The important conclusion that we can reach at this stage, however, is that there seems to be reproductive advantages to being the dominant male in a bi-sexual unit. Given our current understanding, we would characterize the C. vellerosus male competitive regime for mating as between-group contest and mostly within-group scramble, due to the action of female strategies.

Given the strong male-male competition for group membership and the regular takeovers that we have documented in C. vellerosus, we predicted a low occurrence of within-group male coalitions. We also predicted that when males engaged in within-group coalitions, it would be mostly during post-takeover situations when attempting to expel one another (Sterck \& van Hooff, 2000). We expected that coalitions would be formed most often between males that were kin, of high dominance rank, long-term co-residents, that had engaged in parallel transfer, that had affiliative relationships, and 


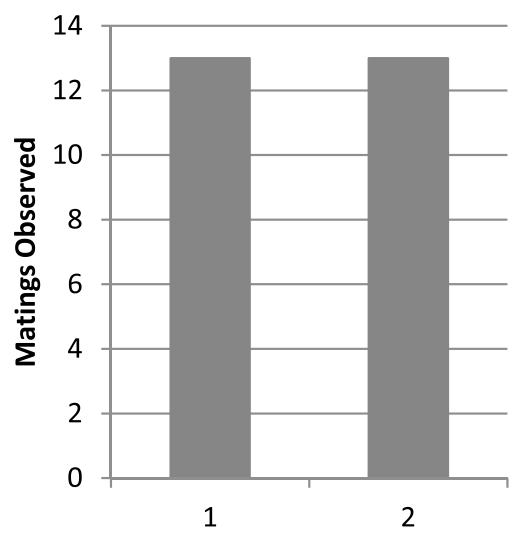

a.

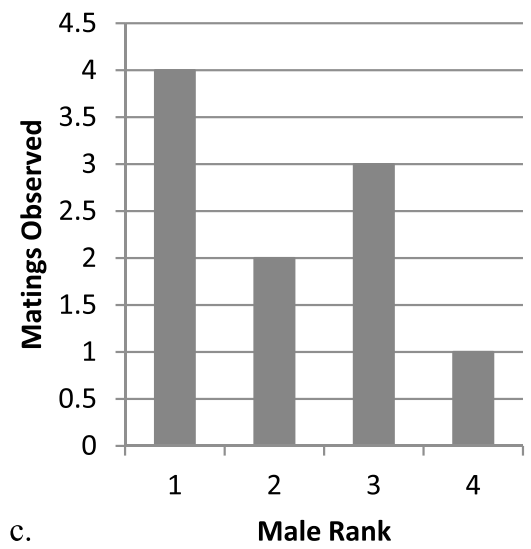

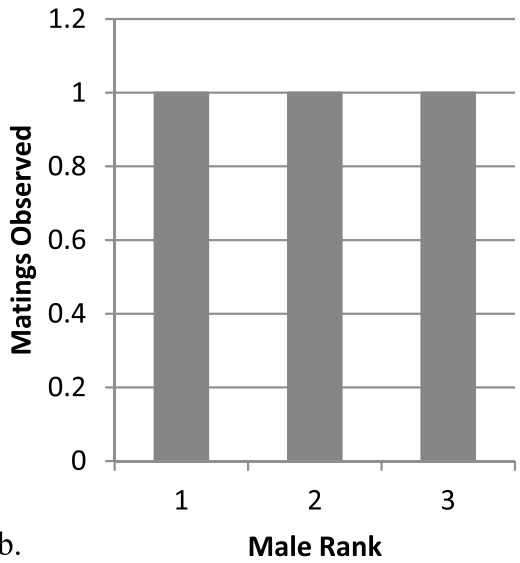

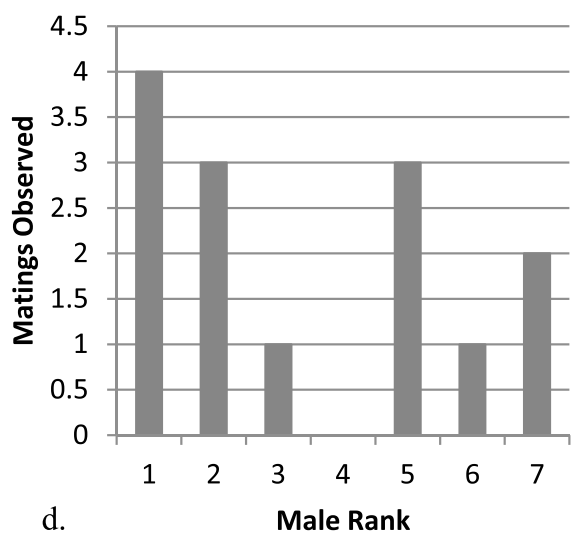

Figure 1. Mating observed in four multi-male, multi-female groups of C. vellerosus from 2004-2005 according to male rank in the hierarchy: (a) RT group, (b) BS group, (c) DA group, (d) WW group.

that rarely showed aggression towards each other (Pusey \& Packer, 1982; Pope, 1990; van Hooff \& van Schaik, 1992; Higham \& Mastrieprieri, 2010). We have observed affiliation among subadult males more often than between adults so we predicted that we would see an effect of age on male affiliation. Male dyads were predicted to be most affiliative when they were kin, of similar age, had been co-resident for a long period of time, or had participated in parallel transfer (e.g., the similarity principle; de Waal \& Lutrell, 1986). Dyads that were the least aggressive, which may have been an indi- 
cation of a good relationship, were also predicted to have higher affiliation rates.

\section{Methods}

\subsection{Study site}

This research was conducted at the Boabeng-Fiema Monkey Sanctuary (BFMS) in central Ghana $\left(7^{\circ} 43^{\prime} \mathrm{N}, 1^{\circ} 42^{\prime} \mathrm{W}\right)$, a dry semi-deciduous forest, 192 ha in size. The BFMS is located at an altitude of $350 \mathrm{~m}$ in the Nkoranza district of the Brong-Ahafo Region. It is surrounded by farmland but connects by a narrow, riparian forest to several smaller forest fragments that also contain populations of $C$. vellerosus. The vegetation is a mosaic of primary forest, regenerating farmland (secondary forest) and woodland (Fargey, 1991; Saj et al., 2005).

\subsection{Study species}

Colobus vellerosus at BFMS have been studied under the supervision of PS since 2000. They are mainly folivorous (annual diet: 74\% leaves; Saj et al., 2005) and group sizes vary (range 9-38, mean 15.0, $N=15$; Wong \& Sicotte, 2006). C. vellerosus lives in bisexual groups that can be uni-male or multi-male with multiple females. All-male bands of short duration also occur in the population (Saj \& Sicotte, 2005; Teichroeb et al., 2011). Groups go through periods of stability without infanticide or male immigrations when their resident male(s) are strong and close to prime age. When a group's male(s) is weakening or aging, new males immigrate and may take over the alpha male position, sometimes leading to a period of instability with female emigrations and infanticides (Teichroeb \& Sicotte, 2008; Teichroeb et al., 2009, 2011, 2012). Between-group encounters are usually aggressive in this species, with adult males as the main participants (Sicotte \& MacIntosh, 2004). Group males, solitary males, and males in all-male bands also attack bisexual groups during male incursions (Sicotte \& MacIntosh, 2004; Teichroeb et al., 2011). Targeted aggression towards infants occurs during between-group encounters and male incursions (Sicotte \& MacIntosh, 2004; Saj \& Sicotte, 2005).

\subsection{Study subjects and data collection}

To examine the most important factors determining strong affiliative relationships and the presence of coalitions among male $C$. vellerosus, we examined 
Table 1.

Study periods and group size.

\begin{tabular}{lcccccr}
\hline Group & Years & $\begin{array}{c}\text { Months } \\
\text { of study }\end{array}$ & $\begin{array}{c}\text { Mean number } \\
\text { of days followed } \\
\text { per month }\end{array}$ & $\begin{array}{c}\text { Number of } \\
\text { follow days }\end{array}$ & $\begin{array}{c}\text { Number of } \\
\text { observation } \\
\text { hours }\end{array}$ & $\begin{array}{c}\text { Group } \\
\text { size } \\
\text { range }\end{array}$ \\
\hline BS & $2003-2010$ & 36 & 3.11 & 112 & 707 & $9-17$ \\
SP & $2006-2010$ & 13 & 2.2 & 29 & 341.9 & $9-17$ \\
RT & $2003-2010$ & 32 & 3.9 & 124 & 825 & $8-27$ \\
OD & $2006-2010$ & 9 & 3 & 26 & 254.8 & $15-20$ \\
DA & $2004-2010$ & 31 & 3.4 & 106 & 873.3 & $17-26$ \\
WW & $2004-2010$ & 27 & 3.7 & 101 & 1086.4 & $23-33$ \\
Total & & 148 & & 498 & 4088.4 & \\
\hline
\end{tabular}

Only years with good individual recognition were included.

interactions in 292 male dyads from 2004 to 2010 in six multi-male, multifemale research groups (Table 1). Groups were followed for varying amounts of time and all adult and subadult individuals could be recognized by features of the face and tail. When researchers were present at the site, each study group was followed for at least one day per month (range 1-17 days, mean 3.22 days/month) for 7-12 h per day (Table 1). Behavioural observations of subadult and adult males were done using 10-min focal samples (Altmann, 1974 ) with no individual sampled more than once per hour (mean number of focal hours per male 1.94, range 0-21.8). As male-male interactions were rare, we also collected behavioural data ad libitum.

A male dyad was included in our sample if they spent at least 3 months co-resident. Both natal and immigrant males were included in the data set. The entire life-histories of some males in our sample were known because they were born into a research group and remained between research groups (36.8\%, $N=28 / 76$ ) but for others that transferred from non-research groups into research groups, entire life-histories were not known (63.2\%, $N=48 / 76$ ). We extracted affiliative and aggressive interactions within male dyads from focal samples and ad libitum data to calculate rates per hour. Ad libitum data were considered valid for calculation of rates of male interactions because males are highly visible members of the group and their interactions are unlikely to be missed. We tested a random selection of dyads to determine if rates of behaviors differed between focal and ad libitum data and found no differences (paired $t$-tests: Affiliation, $N=110$, 
$t=-1.41, p=0.16$; Coalitions, $N=110, t=0.29, p=0.77)$. Affiliative behaviours included allo-grooming and touching. Aggressive behaviours included low-intensity threats (e.g., stiff legs, open mouths, jump displays), and high-intensity contact aggression (e.g., chases, lunges, scratches, grabs, grappling, hits, bites). Coalitions were defined as at least two males jointly showing aggressive behavior towards a third individual or group (the 'target') (de Waal \& Harcourt, 1992). The context of the coalition was defined as 'within-group' when aggression was directed to co-resident individuals. 'Between-group' male coalitions occurred when aggression by at least two within-group males was directed towards extra-group individuals in the context of a male incursion or an inter-group encounter. When more than two males participated in a coalition $(N=1$ triadic interaction), we scored a coalition between each pair of males involved. The characteristics of the dyads (age of the males, dominance rank, level of kinship, if they were from the same age-cohort, had been involved in parallel dispersal, and the length of time they were co-resident in one or more groups) were examined for their influence on the occurrence of affiliation and coalitions. Subadult males were those 3-6 years old that were smaller or the same size as adult parous females, while adult males ( $\geqslant 7$ years old) had achieved full body size (larger than adult females) and regularly participated in loud call bouts with other adult males. The age of some males was known exactly $(36.8 \%, N=28 / 76)$ but for others $(63.2 \%, N=48 / 76)$ age was estimated based on body size. Male dominance relationships were determined from the direction of aggression, displacements, avoidance, and submissive behaviours during focal samples and ad libitum observations. Kinship was determined from partial pedigree information and genetic data (Csillery et al., 2006; Langergraber et al., 2009) from 17 microsatellite loci (for details, see Wikberg et al., 2012). Data on kinship were initially collected for females in the population, so genetic data were only available for 24 male dyads ( $8.2 \%$ of our dyads). Of these 24,7 dyads were known to be unrelated and 17 were kin with variable degrees of relatedness. Information on both maternal and paternal kinship was included when available. We did not always know how males were related but $47 \%(8 / 17)$ were or were suspected of being paternal half-siblings, $17.6 \%(3 / 17)$ were father-son dyads, $17.6 \%(3 / 17)$ were or were suspected of being maternal half-siblings, and the relationship was unknown for $17.6 \%$ of dyads (3/17). Males were only scored as being from the same age-cohort if it was known that they were born in the same group within a year of one 
another. Length of co-residence for each dyad included their total time in the current group and any previous group (if they were known to have transferred in parallel from another study group).

\subsection{Data analyses}

To investigate which factors were most important in determining affiliative relationships and an increased frequency of coalitions among males, we used two Generalized Estimating Equations (GEE) models. GEE's are a type of generalized linear model (GLM) that control for the fact that individual males were repeated within several dyads and allow independent variables to be correlated within each model (Ghisletta \& Spini, 2004; Fitzmaurice \& Verbeke, 2009; Zuur et al., 2009).

In the first GEE model, which was used to determine factors affecting affiliation among male dyads, affiliation rate was the dependent variable and the independent variables were level of kinship, whether or not males were from the same age cohort, length of co-residence, if they had participated in parallel transfer together, and their aggression rate. Kinship was entered into the model as the level of relatedness ( $r$, ranging from 0 to 0.5 ) for dyads were kinship was known and left as missing values for dyads where kinship was unknown.

The same data set was analyzed with a second GEE, this time with coalition rates as the dependent variable and using the following independent variables: rank of dyad, whether or not males were from the same age cohort, length of co-residence, if males had participated in parallel transfer together, affiliation rate, and aggression rate. Few male dyads showed coalitions and for a high proportion of these, level of kinship was not known, so we were unable to analyze the effect of kinship on coalition formation. The rank of the dyad was scored as a binary variable with coalitions between the two highest-ranking males (the alpha and the beta male) given a one and coalitions between other dyads given a zero. In both GEE models, the dependent variables were at the scale level of measurement, were not normally distributed (Shapiro-Wilk tests, $p<0.001$ ), and best conformed to linear distributions, so these distributions were used in the analyses. Dyads were the subject within each model and we controlled for male identity and age of the dyad (subadult-subadult, subadult-adult, or adult-adult) as repeated within-subject factors. Those models with the lowest corrected and uncorrected Quasi Likelihood under Independence Model Criterion (QICC and 
QIC) were considered to have the best goodness of fit (QIC is akin to Akaike Information Criteria (AIC), Hardin \& Hilbe, 2002).

Affiliation and aggression rates were compared between adult male dyads and subadult male dyads using $t$-tests. Random subsets of dyads in each age class were used in statistical tests to ensure that no individual male was repeated within compared dyads. Statistical tests could not be done between these dyads and those that contained an adult and a subadult male because individuals were repeated within dyads, however means are given for comparison. For all analyses, significance was set at 0.05 . Models and statistics were run using SPSS/PASW 17.0.

\section{Results}

\subsection{Affiliation between males}

Affiliation rates between males were higher when the dyad was composed of two subadult males (mean $0.002 / \mathrm{h}$ ) compared to dyads of two adults (mean $0.0002 / \mathrm{h})\left(t\right.$-test: $N_{\text {Adults }}=15, N_{\text {Subadults }}=18, F=7.48, p=$ $0.010)$. Conversely, aggression rates were higher among adult male dyads (mean $0.017 / \mathrm{h})$ than subadult dyads (mean $0.0015 / \mathrm{h})\left(t\right.$-test: $N_{\text {Adults }}=15$, $\left.N_{\text {Subadults }}=18, F=7.43, p=0.010\right)$. When one male in the dyad was subadult and one was adult, affiliation rates $(0.001 / \mathrm{h}, N=118)$ and aggression rates $(0.003 / \mathrm{h})$ fell in the middle of the range (Figure 2$)$.

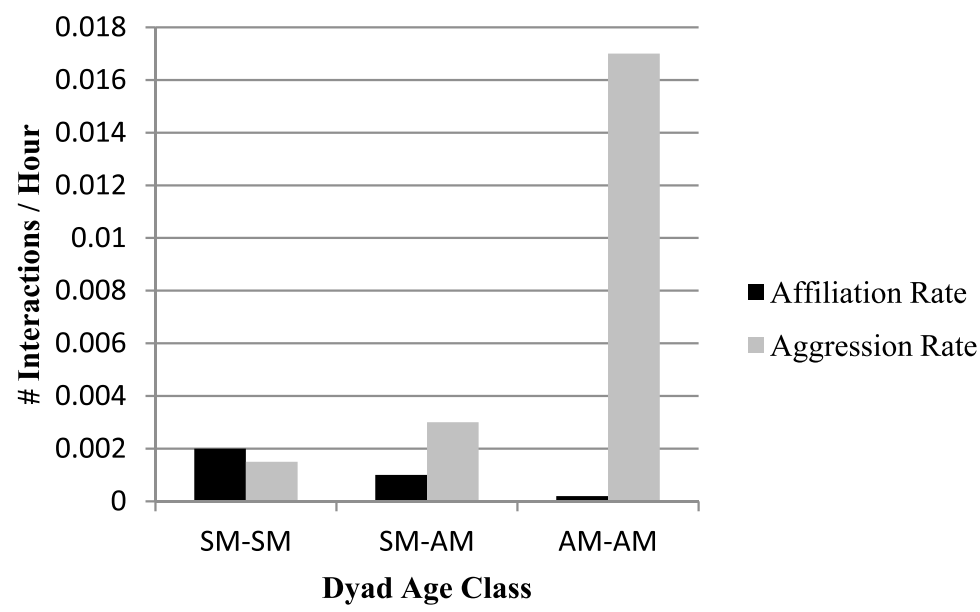

Figure 2. Affiliation rates and aggression rates for dyads of different ages. SM, subadult males; AM, adult males. 
Table 2.

GEE Model examining factors related to affiliation rates between males.

\begin{tabular}{lccc}
\hline Factor & $\beta$ & Wald $\chi^{2}$ & $p$ \\
\hline Kinship level & 0.019 & 3.672 & $0.055^{\mathrm{a}}$ \\
Same age cohort & 0.002 & 0.562 & 0.453 \\
Length of co-residence & -0.00004 & 0.098 & 0.754 \\
Participation in parallel transfer & -0.004 & 2.942 & 0.086 \\
Aggression rate & 0.284 & 1.122 & 0.290 \\
\hline
\end{tabular}

${ }^{\mathrm{a}}$ Trend.

Results of the GEE model for affiliation between males showed that no factor significantly predicted affiliation between males but there was a tendency for male kin to have higher affiliation rates $(\beta=0.019, p=0.055$; Table 2$)$. Affiliation rates were not influenced by aggression rates $(\beta=0.284$, $p=0.290)$, the fact that males had transferred in parallel $(\beta=-0.004, p=$ $0.086)$, the time that the males spent co-resident in a group $(\beta=-0.00004$, $p=0.754)$, or by males being from same age cohort $(\beta=0.002, p=0.453$; Table 2).

\subsection{Male coalitions}

Coalitions were observed in only $7.9 \%$ of dyads $(23 / 291)$ and were primarily directed towards extra-group males ( $93.5 \%$ of events; $29 / 31$ ). During withingroup interactions, coalitions among males were rare (6.5\% of events, $2 / 31)$ occurring in only $1.6 \%(2 / 124)$ of instances of within-group male aggression. The presence of coalitions was more common when both males were adult (14\% of dyads, $14 / 100)$ compared to when one was subadult $(5.9 \%$ of dyads, $7 / 118$ ) or both were subadult (2.7\% of dyads, 2/73) (Figure 3).

The GEE model for coalition rates for each dyad showed that these behaviors occurred more often among high-ranking dyads (made up by the alpha and beta male of a group) ( $\beta=0.383, p=0.014)$. Coalition formation was not influenced by whether or not males were from the same age cohort ( $\beta=-0.015, p=0.288)$, by the fact that they had previously participated in parallel transfer $(\beta=0.040, p=0.196)$, co-residency time $(\beta=0.0004$, $p=0.748)$, affiliation rates $(\beta=-4.164, p=0.094)$, or aggression rates $(\beta=5.665, p=0.090$; Table 3).

Though we were unable to investigate the influence of kinship on coalition formation with the current data set, our limited sample does not imply that 


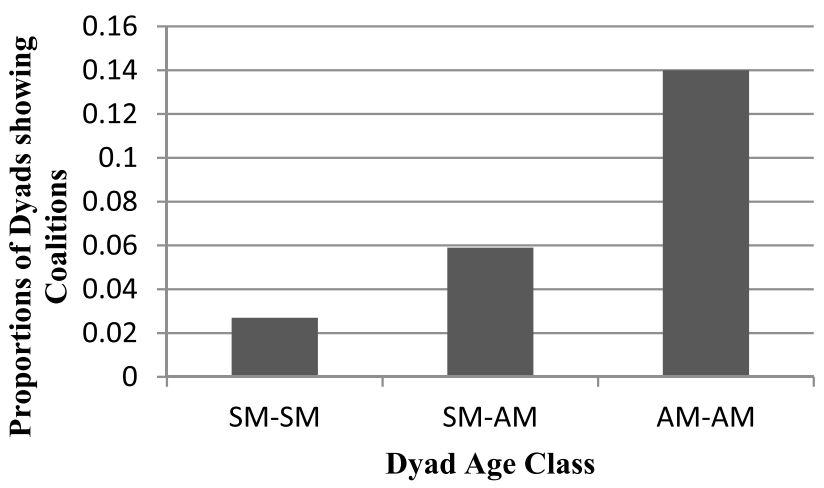

Figure 3. Proportion of dyads that showed coalitions relative to dyad age class. SM, subadult males; AM, adult males.

a relationship between kinship and coalition would be found with a larger sample size (Kin, $N=16$ dyads, Coalition rate $=0.0005 / \mathrm{h}$; Non-Kin, $N=$ 8 , Coalition rate $=0.0005 / \mathrm{h})$.

\section{Discussion}

For $C$. vellerosus, a species in which males disperse from the natal group (Teichroeb et al., 2011), kinship showed a positive tendency to influence the occurrence of affiliative relationships among males. Affiliation among kin is common among primates and can be selected for via increases in inclusive and/or direct fitness (Hamilton, 1964; Chapais, 2001), so the discovery of a relationship between rates of affiliation and kinship is not surprising, in and of itself. What is unexpected about this result is that affiliation tended to oc-

\section{Table 3.}

GEE Model examining factors related to coalition formation between males.

\begin{tabular}{lrrc}
\hline Factor & \multicolumn{1}{c}{$\beta$} & Wald $\chi^{2}$ & $p$ \\
\hline High-ranking dyad & 0.383 & 6.000 & $0.014^{*}$ \\
Same age cohort & -0.015 & 1.131 & 0.288 \\
Length of co-residence & 0.023 & 2.083 & 0.149 \\
Participation in parallel transfer & 0.040 & 1.673 & 0.196 \\
Affiliation rate & -4.164 & 2.808 & 0.094 \\
Aggression rate & 5.665 & 12.215 & 0.090 \\
\hline
\end{tabular}

\footnotetext{
* Significant results $(p<0.05)$.
} 
cur among kin of the dispersing sex (Kapsalis, 2004). Do male C. vellerosus recognize each other as kin and if so, how? Maternal kin recognition may occur through association with the same female and is more common than paternal kin recognition (Holmes \& Sherman, 1983; Strier, 2004), though in uni-male multi-female groups, males may be quite certain of paternity (Smuts \& Gubernick, 1992). Within our small set of male kin, affiliation rates were highest amongst males where kinship could have been more easily recognized (father-son dyads within uni-male, multi-female groups, 0.012/h; maternal half-siblings, $0.010 / \mathrm{h}$ ) when compared with paternal half-siblings $(0.003 / h)$. Though these results should be viewed with caution due to the small sample size, they do suggest a social attraction and a tendency for more positive associations in male kin, even when males disperse from the natal group.

Age was another important factor determining affiliative relationships between males. Young males were affiliative with one another and with adult partners but adult male dyads were less affiliative and more aggressive with one another. This is probably due to the strong reproductive competition between co-resident adult males (Teichroeb \& Sicotte, 2010; Teichroeb et al., 2011), while tolerance and affiliation between adult and subadult males may occur because young males are not yet fully developed (e.g., Macaca sylvanus, Paul, 1989). Though we do not have evidence for an increase in affiliation for $C$. vellerosus males before they dispersed in parallel, a close, long-term relationship would likely have aided males in their attempts to enter bisexual groups (Teichroeb et al., 2011).

The only variable associated with greater rates of coalition formation was high dominance rank. Alpha and beta males were most likely to form coalitions with each other and these coalitions were directed towards extra-group males. Coalition formation was not related to affiliation within a dyad. Indeed, depending on how one defines a statistical trend, males that formed coalitions tended to show higher aggression rates and lower affiliation rates compared to those that did not form coalitions. This clearly suggests that males did not need to have a good relationship, just a common enemy, in order to support one another.

Females actively engage in polyandrous mating and within-group scramble competition for mates occurred between male C. vellerosus (Figure 1; Teichroeb et al., 2005; Teichroeb \& Sicotte, 2010). In this situation, it was predicted and observed that within-group male coalitions would be directed 
towards extra-group males and function to reduce male group size (Pope, 1990; Dias et al., 2010; Berghänel et al., 2010). However, data from one of our groups shows high reproductive skew in favor of the alpha male. If this result can be generalized to other multi-male groups, this certainly would explain why high-ranking males were the ones that usually took on the costs of defending the group from extra-group males, in terms of time, energy, and lost opportunities and why they used coalitions to improve their chances of success in these contests. Even though paternity appears to be highly skewed towards the alpha male, non-alphas get mating access to females and apparently get to sire a small proportion of the infants and, therefore, the beta male might gain some direct fitness benefits from cooperative defense against extra-group males. High-ranking males had more to lose than low-ranking males in the event that male group size increased with male immigration. New immigrant adult males in C. vellerosus tend to achieve high rank quickly and alpha males are often targeted for eviction (Teichroeb et al., 2011). Preventing male immigration likely allowed high-ranking males to maintain their rank and residency for longer time periods and hence to produce more offspring. The future reproductive success of high-ranking males would suffer from a decrease in rank and would certainly suffer if the male was evicted from the group, so these males have more to gain by cooperating against extra-group males than do low-ranking males.

In addition, the most important characteristic of male coalition partners is probably their competence (Chapais, 2006; e.g., Pan troglodytes, Watts, 1998; Mitani et al., 2002) and the most competent partners would be the strongest and, therefore, the highest ranked (Teichroeb \& Sicotte, 2010). Thus, high-ranking coalitions may have been most effective in expelling extra-group male intruders. The direct benefits, in terms of mating access, derived from male coalitions may also mean that kinship is not important in shaping these interactions and that they evolved through mutualism, without reciprocity in support needed (Hamilton, 1964; Trivers, 1971). However, we were unable to investigate the influence of kinship on coalition formation with the current data set.

Male-male cooperation in maintaining access to mates is relatively infrequent but has been reported in some birds and mammals (e.g., Panthera leo, Schaller, 1972; Prunella modularis, Davies, 1992; Tursiops aduncus, Connor et al., 1992; Papio spp., Packer, 1977; Bercovitch, 1988; Nöe \& Sluitjer, 1990; Nöe, 1992; Pan troglodytes, Watts, 1998; Macaca tonkeana, Thierry, 
2007; M. sylvanus, Bissonnette et al., 2011). It is noteworthy though that for C. vellerosus, coalitions between males to access mates were never observed within groups. Rather, males only cooperated in between-group mate defense. Similarly, rank-changing and leveling coalitions (Pandit \& van Schaik, 2003) directed towards other within-group males appear to be quite rare or absent in C. vellerosus. This is curious, since high levels of within-group competition for mates should make it profitable for two lower-ranking males to work together towards a high-ranking target, decreasing his rank, evicting him from the group, or at least distracting him from mate-guarding to allow access to a receptive female (Packer, 1977; Bercovitch, 1986; Noë \& Sluijter, 1990). The costs of these types of coalitions, in terms of time, energy, and risk of injury in fighting or falling from the trees, may be too high for low-ranking males to be beneficial (Broom et al., 2009). Alternatively, male group size may be too small on average for these types of coalitions to have been selected for over evolutionary time (Henzi et al., 1999). Multi-male groups only contain an average of 3.5 adult males and when including unimale groups, the average adult male group size is only 2.3 for $C$. vellerosus at BFMS (9 groups over 237 months of observation; J.A.T. and E.C.W., unpublished data). Female strategies may also decrease the benefit of coalitions for low-ranking males since, when they are not mate-guarded by high-ranking males, females often solicit and achieve copulations with these males (Teichroeb \& Sicotte, 2010). Coalitions among low-ranking males against other resident males probably occur most when males first transfer in parallel to a new group and have to overcome the resistance of resident males (Teichroeb et al., 2011). These interactions were not recorded often in this study due to the sporadic nature of takeovers, but they are known to occur in this population (J.A.T., pers. obs.).

In conclusion, male $C$. vellerosus showed low rates of affiliation and coalitions, which are likely influenced by the fact that all males disperse from the natal group (Teichroeb et al., 2011; Wikberg et al., 2012). Species where males show affiliative relationships are usually those where males are philopatric (see references in the Introduction). Nevertheless, some male dyads did show relatively higher affiliation and coalition rates than others, so $C$. vellerosus, can be added to the growing list of species where relatively strong relationships may occur in the dispersing sex under some circumstances (e.g., Panthera leo, Packer \& Pusey, 1982; Acinonyx jubatus, Caro \& Collins, 1987; Herpestes sanquineus, Rood, 1989; Helogale parvula, Rood, 
1990; Tursiops aduncus, Connor et al., 1992; Möller \& Beheregaray, 2004; Saimiri sciureus, Mitchell, 1994; Macaca radiata, Silk, 1994; Adiseshan et al., 2011; M. assamensis, Schülke et al., 2010; Cebus capucinus, Jack \& Fedigan, 2004; Pan troglodytes, Lehmann \& Boesch, 2008).

\section{Acknowledgements}

We would like to thank Kathy Jack and Erin Riley for their invitation to submit to the IPS symposium on male social tolerance. Permission to conduct this research was provided by the Ghana Wildlife Division and the management committee of the Boabeng-Fiema Monkey. Research assistance was provided by Lauren Brent, Rachel Boratto, Robert Koranteng, Kwame Duodo, Kwaku Amponsah, Johanna Hedlund, Danica Stark, Lucy Anderson, Fernando Campos and Teresa Holmes. We are grateful to Tak Fung for help with statistics. This paper also benefitted from the comments of two anonymous reviewers. Data collection methods complied with the rules of the University of Calgary's Animal Care Committee and with the laws of Ghana. Funding was provided by Alberta Ingenuity, American Society of Primatologists, International Primatological Society, Leakey Foundation, Natural Sciences and Engineering Research Council of Canada, Province of Alberta, Sweden-America Foundation, University of Calgary, and the Wenner-Gren Foundation.

\section{References}

Adiseshan, A., Adiseshan, T. \& Isbell, L.A. (2011). Affiliative relationships and reciprocity among adult male bonnet macaques (Macaca radiata) at Arunachala Hill, India. - Am. J. Primatol. 73: 1107-1113.

Altmann, J. (1974). Observational study of behaviour: sampling methods. - Behaviour 49: 227-267.

Bercovitch, F.B. (1986). Male rank and reproductive activity in savanna baboons. - Int. J. Primatol. 7: 533-550.

Bercovitch, F.B. (1988). Coalitions, cooperation and reproductive tactics among adult male baboons. - Anim. Behav. 36: 229-234.

Berghänel, A., Schülke, O. \& Ostner, J. (2010). Coalition formation among Barbary macaque males: the influence of scramble competition. - Anim. Behav. 80: 675-682.

Bissonnette, A., Bischofberger, N. \& van Schaik, C.P. (2011). Mating skew in Barbary macaque males: the role of female mating synchrony, female behaviour, and male-male coalitions. - Behav. Ecol. Sociobiol. 65: 167-182. 
Bissonnette, A., de Vries, H. \& van Schaik, C.P. (2009). Coalitions in male Barbary macaques, Macaca sylvanus: strength, success and rules of thumb. - Anim. Behav. 78: 329-335.

Boinski, S. (1994). Affiliation patterns among male Costa Rican squirrel monkeys. — Behaviour 130: 191-209.

Broom, M., Koenig, A. \& Borries, C. (2009). Variation in dominance hierarchies among group-living animals: modeling stability and the likelihood of coalitions. - Behav. Ecol. 20: 844-855.

Caro, T. \& Collins, D. (1987). Male cheetah social organization and territoriality. — Ethology 74: 52-64.

Chapais, B. (2001). Primate nepotism: what is the explanatory value of kin selection? - Int. J. Primatol. 22: 203-229.

Chapais, B. (2006). Kinship, competence and cooperation in primates. - In: Cooperation in primates and humans (Kappeler, P.M. \& van Schaik, C.P., eds). Springer, Heidelberg, p. 47-64.

Clarke, P., Pradhan, G. \& van Schaik, C. (2009). Intersexual conflict in primates: infanticide, paternity allocation, and the role of coercion. - In: Sexual coercion in primates and humans: an evolutionary perspective on male aggression against females (Muller, M.N. \& Wrangham, R.W., eds). Harvard University Press, Cambridge, MA, p. 42-77.

Connor, R.C., Smolker, R.A. \& Richards, F. (1992). Dolphin alliances and coaltions. — In: Coalitions and alliances in humans and other animals (Harcourt, A.H. \& de Waal, F.B.M., eds). Oxford University Press, Oxford, p. 415-444.

Cords, M. (2000). The number of males in guenon groups. - In: Primate males: causes and consequences of variation in group composition (Kappeler, P.M., ed.). Cambridge University Press, Cambridge, p. 84-96.

Csillery, K., Johnson, T., Beralki, D., Clutton-Brock, T., Coltman, D., Hansson, B., Spong, G. \& Pemberton, J.M. (2006). Performance of marker-based estimators in natural populations of outbred vertebrates. — Genetics 173: 2091-2101.

Davies, N.B. (1992). Dunnock behavior and social evolution. — Oxford University Press, Oxford.

de Waal, F.B.M. \& Harcourt, A.H. (1992). Coalitions and alliances: a history of ethological research. - In: Coalitions and alliances in humans and other animals (Harcourt, A.H. \& de Waal, F.B.M., eds). Oxford University Press, Oxford, p. 1-19.

de Waal, F.B.M. \& Lutrell, L.M. (1986). The similarity principle underlying social bonding among female rhesus monkeys. - Folia Primatol. 46: 215-234.

Dias, P.A.D., Rangel-Negrin, A., Veà, J.J. \& Canales-Espinosa, D. (2010). Coalitions and male-male behavior in Alouatta palliata. — Primates 51: 91-94.

Dunbar, R.I.M. (1984). Reproductive decisions: an economic analysis of gelada baboon social strategies. - Princeton University Press, Princeton, NJ.

Emlen, S.T. \& Oring, I.W. (1977). Ecology, sexual selection and evolution of mating systems. — Science 197: 215-223. 
Fargey, P.J. (1991). Assessment of the conservation status of the Boabeng-Fiema Monkey Sanctuary. - Final report to the Flora and Fauna Preservation Society, University of Science and Technology, Kumasi.

Fitzmaurice, G. \& Verbeke, G. (2009). Generalized estimating equations for longitudinal data analyses. — In: Longitudinal data analysis (Fitzmaurice, G., Davidian, M., Verbeke, G. \& Molenberghs, G., eds). Chapman and Hall, Boca Raton, FL, p. 43-78.

Furuichi, T. \& Ihobe, H. (1994). Variation in male relationships in bonobos and chimpanzees. - Behaviour 130: 211-228.

Ghisletta, P. \& Spini, D. (2004). An introduction to Generalized Estimating Equations and an application to assess selectivity effects in a longitudinal study on very old individuals. J. Educ. Behav. Stat. 29: 421-437.

Goodall, J. (1986). The chimpanzees of Gombe: patterns of behavior. - Harvard University Press, Cambridge, MA.

Greenwood, P.G. (1980). Mating systems, philopatry, and dispersal in birds and mammals. — Anim. Behav. 28: 1140-1162.

Hamilton, W.D. (1964). The genetical theory of social behavior I and II. - J. Theor. Biol. 7: $1-52$.

Hardin, J.W. \& Hilbe, J.M. (2002). Generalized estimating equations. — Chapman and Hall, Boca Raton, FL.

Henzi, S.P., Clarke, P.M.R., van Schaik, C.P., Pradhan, G.R. \& Barrett, L. (2010). Infanticide and reproductive restraint in a polygynous social mammal. — Proc. Natl. Acad. Sci. USA 107: 2130-2135.

Henzi, S.P., Weingrill, T. \& Barrett, L. (1999). Male behavior and the evolutionary ecology of chacma baboons. - S. Afr. J. Sci. 95: 240-242.

Higham, J.P. \& Maestripieri, D. (2010). Revolutionary coalitions in male rhesus macaques. — Behaviour 147: 1889-1908.

Hill, D.A. (1994). Affiliative behaviour between adult males of the genus Macaca. - Behaviour 130: 293-308.

Holmes, T.D. (2011). Dispersal in a fragmented habitat: the spatial genotypic structure of Colobus vellerosus at Boabeng-Fiema Monkey Sanctuary, Ghana. - Master's Thesis, University of Calgary, Calgary, AB.

Holmes, W.G. \& Sherman, P.W. (1983). Kin recognition in animals: the prevalence of nepotism among animals raises basic questions of how and why they distinguish relative from unrelated individuals. - Am. Sci. 71: 46-55.

Isbell, L.A. \& Van Vuren, D. (1996). Differential costs of locational and social dispersal and their consequences for female group-living primates. - Behaviour 133: 1-36.

Jack, K.M. \& Fedigan, L.M. (2004). Male dispersal patterns in white-faced capuchins, Cebus capucinus. Part 1: patterns and causes of natal emigration. - Anim. Behav. 67: 761-769.

Kapasalis, E. (2004). Matrilineal kinship and primate behavior. — In: Kinship and behavior in primates (Chapais, B. \& Berman, C.M., eds). Oxford University Press, Oxford, p. 153176.

Langergraber, K., Mitani, J. \& Vigilant, L. (2009). Kinship and social bonds in female chimpanzees (Pan troglodyetes). - Am. J. Primatol. 71: 840-851. 
Lehmann, J. \& Boesch, C. (2008). Sexual differences in chimpanzee sociality. — Int. J. Primatol. 29: 65-81.

Mitani, J.C., Watts, D.P., Pepper, J.W. \& Merriwether, D.A. (2002). Demographic and social constraints on male chimpanzee behaviour. - Anim. Behav. 64: 9-25.

Mitchell, C.L. (1994). Migration alliances and coalitions among male South American squirrel monkeys (Saimiri sciureus). — Behaviour 130: 169-190.

Möller, L.M. \& Beheregaray, L.B. (2004). Genetic evidence for sex-biased dispersal in resident bottlenose dolphins (Tursiops aduncus). — Mol. Ecol. 13: 1607-1612.

Nöe, R.A. (1992). Alliance formation among male baboons: shopping for profitable partners. — In: Coalitions and alliances in humans and other animals (Harcourt, A.H. \& de Waal, F.B.M., eds). Oxford University Press, Oxford, p. 285-321.

Nöe, R. \& Sluijter, A.A. (1990). Reproductive tactics of male savanna baboons. - Behaviour 113: $117-170$.

Nunn, C.L. (1999). The number of males in primate social groups: a comparative test of the socioecological model. — Behav. Ecol. Sociobiol. 46: 1-13.

Olson, L.E. \& Blumstein, D.T. (2009). A trait-based approach to understand the evolution of complex coalitions in male mammals. - Behav. Ecol. 20: 624-632.

Packer, C. (1977). Reciprocal altruism in Papio anubis. - Nature 265: 441-443.

Packer, C. \& Pusey, A.E. (1982). Cooperation and competition within coalitions of male lions: kin selection or game theory? - Nature 296: 740-742.

Pandit, S.A. \& van Schaik, C.P. (2003). A model for levelling coalitions among primate males: toward a theory of egalitarianism. - Behav. Ecol. Sociobiol. 55: 161-168.

Paul, A. (1989). Determinants of male mating success in a large group of Barbary macaques (Macaca sylvanus) at Affenberg Salem. — Primates 30: 461-476.

Pope, T.R. (1990). The reproductive consequences of male cooperation in the red howler monkey: paternity exclusion in multi-male and single-male troops using genetic markers. — Behav. Ecol. Sociobiol. 27: 239-446.

Rood, J.P. (1989). Male association in a solitary mongoose. — Anim. Behav. 38: 725-727.

Rood, J.P. (1990). Group size, survival, reproduction and routes to breeding in dwarf mongooses. - Anim. Behav. 39: 566-572.

Saj, T.L. \& Sicotte, P. (2005). Male takeover in Colobus vellerosus at Boabeng-Fiema Monkey Sanctuary, central Ghana. - Primates 46: 211-214.

Saj, T.L., Teichroeb, J.A. \& Sicotte, P. (2005). The population status of the ursine colobus (Colobus vellerosus) at Boabeng-Fiema, Ghana. - In: Commensalism and conflict: the human primate interface (Paterson, J.D. \& Wallis, J., eds). American Society of Primatologists, Norman, OK, p. 350-375.

Schaller, G. (1972). The Serengeti lion: a study of predator-prey relations. - University of Chicago Press, Chicago, IL.

Schülke, O., Bhagavatula, J., Vigilant, L. \& Ostner, J. (2010). Social bonds enhance reproductive success in male macaques. - Curr. Biol. 20: 1-4.

Sicotte, P. (1993). Inter-group encounters and female transfer in mountain gorillas: influence of group composition on male behavior. - Am. J. Primatol. 30: 21-36. 
Sicotte, P. \& MacIntosh, A.J. (2004). Inter-group encounters and male incursions in Colobus vellerosus in central Ghana. - Behaviour 141: 533-553.

Sicotte, P., Teichroeb, J.A. \& Saj, T.L. (2007). Aspects of male competition in Colobus vellerosus: preliminary data on male and female loud calling, and infant deaths after a take-over. — Int. J. Primatol. 28: 627-636.

Silk, J.B. (1994). Social relationships of male bonnet macaques: male bonding in a matrilineal society. - Behaviour 130: 270-291.

Smith, J.E., Van Horn, R.C., Powning, K.S., Cole, A.R., Graham, K.E., Memenis, S.K. \& Holekamp, K.E. (2010). Evolutionary forces favoring intragroup coalitions among spotted hyenas and other animals. - Behav. Ecol. 21: 284-303.

Smuts, B.B. \& Gubernick, D.J. (1992). Male-infant relationships in nonhuman primates: paternal investment or mating effort? — In: Father-child relations: cultural and biosocial contexts (Hewlett, B.S., ed.). Aldine de Gruyter, New York, NY, p. 1-30.

Sterck, E.H.M. \& van Hooff, J.A.R.A.M. (2000). Then number of males in langur groups: monopolizability of females or demographic processes? - In: Primate males (Kappeler, P.M., ed.). Cambridge University Press, Cambridge, p. 120-129.

Strier, K.B. (1990). New World primates, new frontiers: insights from the woolly spider monkey, or muriqui (Brachyteles arachnoides). — Int. J. Primatol. 11: 7-19.

Strier, K.B. (2004). Patrilineal kinship and primate behavior. — In: Kinship and behavior in primates (Chapais, B. \& Berman, C.M., eds). Oxford University Press, Oxford, p. 177199.

Symington, M.M. (1990). Fission-fusion social organization in Ateles and Pan. - Int. J. Primatol. 11: 47-61.

Teichroeb, J.A., Marteinson, S. \& Sicotte, P. (2005). Individuals' behaviors following dyemarking in wild black-and-white colobus (Colobus vellerosus). - Am. J. Primatol. 65: 197-203.

Teichroeb, J.A. \& Sicotte, P. (2008). Infanticide in ursine colobus monkeys (Colobus vellerosus): new cases and a test of the existing hypotheses. - Behaviour 145: 727-755.

Teichroeb, J.A. \& Sicotte, P. (2010). The function of male agonistic displays in ursine colobus monkeys (Colobus vellerosus): male competition, female mate choice or sexual coercion? —Ethology 116: 366-380.

Teichroeb, J.A., Wikberg, E.C. \& Sicotte, P. (2009). Female dispersal patterns in six groups of ursine colobus (Colobus vellerosus): infanticide avoidance is important. - Behaviour 146: 551-582.

Teichroeb, J.A., Wikberg, E.C. \& Sicotte, P. (2011). Dispersal in male ursine colobus monkeys (Colobus vellerosus): influence of age, rank and contact with other groups on dispersal decisions. - Behaviour 148: 765-793.

Teichroeb, J.A., Wikberg, E.C., Bădescu, I., MacDonald, L.J. \& Sicotte, P. (2012). Infanticide risk and male quality influence optimal group composition for Colobus vellerosus. Behav. Ecol. 23: 1348-1359.

Thierry, B. (2007). The macques: a double-layered social organization. — In: Primates in perspective, 2nd edn. (Campbell, C., Fuentes, A., MacKinnon, K.C., Panger, M. \& Bearder, S., eds). Oxford University Press, Oxford, p. 229-240. 
Trivers, R.L. (1971). The evolution of reciprocal altruism. — Q. Rev. Biol. 46: 35-57.

van Hooff, J.A.R.A.M. \& van Schaik, C.P. (1992). Cooperation in competition: the ecology of primate bonds. - In: Coalitions and alliances in humans and other animals (Harcourt, A.H. \& de Waal, F.B.M., eds). Oxford Univeristy Press, Oxford, p. 357-390.

van Hooff, J.A.R.A.M. \& van Schaik, C.P. (1994). Male bonds: affiliative relationships among nonhuman primate males. - Behaviour 130: 309-337.

van Schaik, C.P., Pandit, S. \& Vogel, E. (2006). Toward a general model for male-male coalitions in primate groups. - In: Cooperation in primates and humans (Kappeler, P.M. \& van Schaik, C.P., eds). Springer, Heidelberg, p. 151-172.

Watts, D.P. (1998). Coalitionary mate guarding by male chimpanzees at Ngogo, Kibale National Park, Uganda. - Behav. Ecol. Sociobiol. 44: 43-55.

Watts, D.P. (2000a). Grooming between male chimpanzees at Ngogo, Kibale National Park, Uganda. II. Male rank and priority of access to partners. — Int. J. Primatol. 21: 211-238.

Watts, D.P. (2000b). Causes and consequences of variation in male mountain gorilla life histories and group membership. - In: Primate males (Kappeler, P.M., ed.). Cambridge University Press, Cambridge, p. 169-180.

Wikberg, E.C., Sicotte, P., Campos, F.A. \& Ting, N. (2012). Between-group variation in female dispersal, kin composition of groups, and proximity patterns in a black-and-white colobus monkey (Colobus vellerosus). — PloS One 7: e48740.

Wong, S.N.P. \& Sicotte, P. (2006). Population size and density of Colobus vellerosus at the Boabeng-Fiema Monkey Sanctuary and surrounding forest fragments in Ghana. - Am. J. Primatol. 68: 465-476.

Zuur, A.F., Ieno, E.N., Walker, N., Saveliev, A.A. \& Smith, G.M. (eds) (2009). Generalized estimating equations. - In: Mixed effects modes and extensions in ecology with R. Springer, New York, NY, Chapter 13, p. 295-321. 